\title{
Visiones Docentes sobre la Participación de Familias Migrantes en la Escuela Chilena
}

\section{Teachers' Visions on the Participation of Migrant Families in the Chilean School}

\author{
María Loreto Mora-Olate * \\ Universidad Autónoma de Chile, Chile
}

\begin{tabular}{ll}
\hline DESCRIPTORES: & RESUMEN: \\
Docente & El estudio tiene como objetivo describir las visiones de los docentes sobre la participación de \\
Familia & las familias migrantes en la escuela, en términos de cómo esta establece mecanismos de vin- \\
Migración & culación con los padres y cómo ellos participan en el proceso escolar de sus hijos/as. Comple- \\
Escuela & mentariamente, se indaga en las capacitaciones para docentes en Educación Intercultural. \\
Chile & Esta investigación de tipo cualitativa configura un estudio de caso con nueve docentes perte- \\
& necientes al liceo municipal de enseñanza secundaria con mayor concentración de matrícula \\
& de alumnado hijo/a de personas migrantes en Chillán, capital regional de Nuble (Chile); te- \\
& rritorio que presenta un creciente aumento de su población extranjera. Los resultados indi- \\
& can que los docentes manifiestan visiones contrapuestas sobre la participación de las fami- \\
& lias migrantes. La visión positiva, constata dicha participación que responde a la normativa \\
& del liceo, valorando en los apoderados extranjeros su actitud más bien sumisa a las normas \\
& del establecimiento. Emerge también una visión negativa, que apunte a la ausencia de parti- \\
& cipación de los padres inmigrantes, quienes, a juicio de los docentes, se ven constreñidos por \\
& sus compromisos laborales. Ambas visiones derivan de una relación escuelocéntrica entre \\
& docentes y familias, donde la escuela establece mecanismos de inducción estandarizada de \\
& las familias inmigradas, resultando estas invisibilizadas. A su vez, los discursos docentes re- \\
& velan una ausencia formativa en Educación Intercultural en contextos de migración.
\end{tabular}

\section{KEYWORDS:}

Teacher

Family

Migration

School

Chile

\section{ABSTRACT:}

The study aims to describe the teachers' views on the participation of migrant families in the school, in terms of how it establishes linkage mechanisms with parents and how they participate in the school process of their children. In addition, it investigates the training for teachers in Intercultural Education. This qualitative research configures a case study with nine teachers from the municipal secondary school with the highest concentration of student enrollment of migrant children in Chillán, regional capital of Nuble (Chile); territory that presents a growing increase in its foreign population. The results indicate that teachers express conflicting views on the participation of migrant families. The positive vision confirms said participation that responds to the regulations of the high school, valuing in foreign proxies their attitude rather submissive to the rules of the establishment. A negative vision also emerges, pointing to the lack of participation of immigrant parents, who, in the teachers' opinion, are constrained by their work commitments. Both visions derive from a school-centered relationship between teachers and families, where the school establishes standardized induction mechanisms for immigrant families, making them invisible. In turn, teaching discourses reveal a lack of training in Intercultural Education in migration contexts.

\section{CÓMO CITAR:}

Mora-Olate, M. L. (2021). Visiones docentes sobre la participación de familias migrantes en la escuela chilena. REICE. Revista Iberoamericana sobre Calidad, Eficacia y Cambio en Educación, 19(3), 19-31.

https://doi.org/10.15366/reice2021.19.3.002

${ }^{*}$ Contacto: maria.mora@uautonoma.cl

ISSN: 1696-4713

revistas.uam.es/reice 


\section{Introducción}

Desde que Chile recuperó su democracia en la década los noventa, se ha ido transformando en un país receptor de personas extranjeras, que han arribado al territorio en busca de mejores condiciones de vida. Según los resultados del Censo 2017, entre 1990 y 1999 la cantidad de inmigrantes internacionales sumaban 59.949; en el periodo comprendido entre el 2000 y 2009, la cifra aumentó a 129.024 extranjeros y entre 2010 y 2017, su número alcanzó a 471.285 personas extranjeras que representan el 4,35\% de la población total de Chile; en cambio, en el Censo del año 2002, el 1, 27\% de la población era inmigrante (INE, 2018 , p. 9). El informe censal también destaca que el $66,7 \%$ de los inmigrantes que actualmente residen en el país, arribaron en el periodo 2010-2017, concentrándose el 61\% de los casos entre 2015 y 2017 (hasta la fecha del censo, 19 de abril). Según el país de nacimiento, la gran parte proviene de Perú, Colombia y Venezuela (INE, 2018, p. 10). Las regiones que concentran los mayores porcentajes de la población total extranjera son la región Metropolitana $(65,2 \%)$ y las ubicadas en el norte de Chile, Antofagasta $(8,4 \%)$ y Tarapacá $(5,9 \%)$. No obstante, la migración internacional está marcando presencia en todas las regiones del país y es así como, en la naciente región de Ñuble, residen 3.736 extranjeros, que equivalen al 0,8 \% de la población total (INE, 2018, p. 11).

La inmigración predominantemente latinoamericana que experimenta Chile tiene su correlato en el sistema escolar, particularmente en establecimientos municipalizados, donde arriban mayoritariamente las familias migrantes, como es el contexto del caso de estudio que se desarrolla en esta comunicación. Es así como la matrícula de estudiantes extranjeros a nivel nacional ha experimentado un aumento considerable: en 2014 se encontraban matriculados 22.425 estudiantes extranjeros; en 2015, un total de 30.625, duplicándose la cifra en 2016 con 61.086 y en 2017 la matrícula llegó a 77.608 (Mineduc, 2018a). Este aumento de la matrícula se observa especialmente en el sector municipalizado, donde el $57 \%$ de los estudiantes extranjeros están matriculados, aumentado su tasa de 1,5\% el año 2015 al 3,5\% el 2017, lo cual ha contribuido a la estabilización de la matrícula, municipal, pero a su vez ha levantado la necesidad de observar y analizar con mayor profundidad el nuevo contexto de estas comunidades educativas (Mineduc, 2018a).

La elocuencia de la realidad sistematizada en cifras nos revela la creciente llegada de familias extranjeras a Chile especialmente durante la última década marcando su presencia no solo en la región Metropolitana o en las regiones fronterizas del norte de Chile, sino también en todas las regiones del país (INE, 2018). A nivel de las regiones, en cada una de ellas la matrícula de estudiantes extranjeros como porcentaje de la matrícula total ha experimentado un aumento entre 2015 y 2017 (Mineduc, 2018a). Si bien, debido a la mayor concentración de población inmigrante en las regiones ya mencionadas, se entiende que la distribución de la matrícula escolar también radique en ellas. Sin embargo, hacia "el sur del país la cantidad de estudiantes extranjeros disminuye, las ciudades como Chillán y Concepción constituyen casos excepcionales, ya que concentrarían una cantidad total relativamente alta de extranjeros por ser ciudades grandes" (Mineduc, 2018a, p. 25).

En el caso de Chillán, capital de la recientemente creada Región de Ñuble, si bien la cantidad de estudiantes extranjeros no presenta cifras altas, sí se observa un crecimiento constante de la matrícula en establecimientos municipalizados: en el año 2015 con 7 estudiantes, aumentando a 21 en 2016 y en el año 2017 la matrícula llegó a 65 estudiantes extranjeros. En 2018, la matrícula alcanza 173 y hasta abril del año 2019, 270 estudiantes provenientes en su mayoría de Venezuela, Perú y Colombia (DAEM, 2019).

El ingreso al sistema escolar de hijos de personas que migran constituye un hito relevante para las familias, porque la escuela connota una puerta de inclusión en la sociedad de acogida (García-Yepes, 2017). A su vez, la relación entre la escuela y las familias es considerada como un aspecto fundamental en el proceso formativo de los niños/as y jóvenes (Gubbins, 2016; Nakamura, 2011; Viveros y Cárcamo, 2019).

Teniendo en cuenta los antecedentes planteados, interesa plantear una indagación más intensiva que extensiva, que permita describir las visiones de los docentes sobre la participación de las familias migrantes en la escuela, considerando un territorio como la ciudad de Chillán (Chile), donde la inmigración aún es emergente, pero que ha ido experimentado un aumento en los últimos cinco años, hecho que tiene un correlato en el sistema escolar. 


\section{Revisión de la literatura}

\subsection{Política educativa y migración}

Chile se regía por una Ley de Extranjería del 1975. El segundo gobierno de Sebastián Piñera promulgó la nueva Ley n²1325 de Migración y Extranjería. En el ámbito educativo, el Estado de Chile en su Constitución Política, actualmente en proceso constituyente, decreta el derecho a la educación escolar para todos los niños/as y jóvenes extranjeros, indepen-diente de la situación migratoria de sus padres. Al no contar con una política educativa que orientara el trabajo en aula con estudiantes migrantes, desde el Ministerio de Educación esta temática comenzó a ser vinculada al ámbito de la inclusión educativa, a propósito de la Ley de Inclusión (Mineduc, 2016). No obstante, la evidencia investigativa en Chile, como concluyen Joiko y Vásquez (2016), defiende que "existen más acciones de integración que de inclusión, dadas las lógicas asimilacionistas propias de la cultura escolar, con un fuerte énfasis, por ejemplo, en un currículo nacionalista y monocultural, con menos espacios para el diálogo del otro diferente, tanto cultural como socialmente" (p. 139). Es decir, el Estado de Chile ha permanecido silente en materia educativa frente a la llegada de hijos/as de personas migrantes al país (Mora-Olate, 2018).

La nueva administración de gobierno ha presentado el documento "Política Nacional de estudiantes extranjeros" (Mineduc, 2018b), el cual declara que "consolida el camino recorrido por el Ministerio de Educación para la construcción” (p. 3) de esta Política. Busca entregar un marco referencial, que a jui-cio de dicha política "favorece el acceso, la permanencia y las trayectorias educativas de este grupo de especial protección dentro del sistema educacional chileno, generando dispositivos que den respuesta a necesidades particulares de las distintas comunidades educativas que lo integran, mediante la propia reflexión y análisis" (Mineduc, 2018b, p. 3).

Esta Política ha resultado discutible en cuanto a su aporte en la práctica pedagógica del día a día en las escuelas (Beniscelli, Riedemann y Stang, 2019), emergiendo sugerencias de ser revisada desde un enfoque de derechos y de educación intercultural (Cisternas, Jara y Vuollo, 2019). Otras voces la han considerado solo como una especie de recopilación histórica de aspectos como: el panorama estadís-tico de los estudiantes extranjeros en el sistema educativo, las normativas nacionales y referentes in-ternacionales que darían sustento al trabajo con esta población, además de solamente enunciar las definiciones metodológicas para la gestión de la Política en cuestión y los desafíos que ello involucra (Mora-Olate, 2020).

Sin embargo, entre los diagnósticos que dieron insumos para dicha Política, provenientes de la eviden-cia investigativa, es posible rescatar aquellos que apuntan a la importancia del trabajo con las fami-lias migrantes, porque "si bien los profesores son fundamentales en el éxito de los estudiantes en las escuelas, también lo son los padres y madres. Los estudiantes logran mejores resultados cuando éstos entienden la importancia de la escolaridad, cómo funciona el sistema escolar y cómo apoyar mejor el progreso de sus hijos en la escuela" (Mineduc, 2018b, p. 15).

En coherencia con dicho aspecto, dentro de las definiciones metodológicas para la gestión de la "Política Nacional de Estudiantes Extranjeros", se establece como una de las áreas de gestión en el sistema escolar, el Fortalecimiento de la Gestión Educativa, consignándose como primer objetivo "promover una convivencia escolar que valore la diversidad e integre colaborativamente a estudiantes extranjeros y sus familias” (Mineduc, 2018 b), p. 27). A su vez, entre los desafíos se indican demandas al área de gestión educativa, entre ellas, "emitir orientaciones para la elaboración de protocolos de acogida tras-versales e independientes de las voluntades políticas de los establecimientos educativos” (Mineduc, 2018 b), p. 30), o del arbitrio o ideología de los docentes, como lo constata la evidencia empírica (Beech y Princz, 2012).

\subsection{Participación de las familias en la escuela}

A pesar de la definición de escuela como un espacio central para la integración social (Stefoni et al., 2010), históricamente la relación escuela y familia ha estado caracterizada por la asimetría, ellas han marcado su distancia a pesar de que se necesitan (Garreta, 2017). Giró y Andrés (2017) afirman que dicha asimetría obedece a que en la comunicación (y relación) entre el profesorado y las familias, estas se perciben en un plano inferior y la cultura escolar, se halla desprovista de un cuerpo teórico-práctico 
sobre la participación y sus formas, resultado la formación de los docentes y de las familias un punto débil: "los profesores se involucran en función de su filosofía o sus motivaciones y, en consecuencia, es una cuestión de personalidad, porque no hay formación específica para la participación de familias y docentes” (Giró y Andrés, 2017, p. 131). Por lo tanto, precisan Giró y Andrés (2017), la relación entre los docentes y las familias se fundamenta más bien en el sentido común y en las experiencias pasadas.

La participación de las familias también se viene valorando como un factor indicador vinculado a la calidad de la educación (Colás y Contreras, 2013), en un sentido más amplio, y no meramente restringido al rendimiento académico (Gubbins, 2016). La evidencia investigativa viene indicando con fuerza que la participación de este grupo debe ser considerado, pero es necesario que la investigación "deba definir con precisión los términos, especificando qué actividades se incluyen bajo el rubro participación de las familias y de los padres, madres y apoderados en particular. Igualmente, que ella debiera especificar los resultados y metas que se persiguen con su participación (Gubbins, 2016, p. 47).

Siguiendo a Gubbins (2016), la noción de participación tiende a aludir a los vínculos que se van construyendo entre las personas motivadas por la consecución de una meta común, estableciéndose relaciones recíprocas. Dicha reciprocidad, entonces resulta ser "una responsabilidad compartida entre escuela y familia en la educación, desde la acción que ejercen las familias y desde la acción que ejercen las escuelas" (Vigo, Dieste y Julve, 2017, p. 150).

El profesorado no ha incorporado el discurso de la participación de las familias en su práctica cotidiana, a juicio de Giró y Andrés (2017), por el peso de la formación inicial que no aborda dicha temática "o se hacía parcialmente, o quizá por las actitudes de resistencia hacia la implicación/participación de las familias en las tareas de gestión de los centros escolares" (p. 129). No obstante, los docentes juegan un rol preponderante para el fomento de la participación de las familias en la escuela. Del profesorado se espera una actitud receptiva "para reconocer los valores y potencialidades de las familias que contribuye a que los padres estén implicados y que no queden excluidos" (Vigo, Dieste y Julve, 2017, p. 155); aspecto que resulta de mayor interés para el caso de las familias migrantes, donde "el reconocimiento y el respeto de las culturas migrantes en los centros contribuye a la participación de las familias y los logros de los alumnos” (p. 155).

Como condición de lo anterior, la comunicación entre los agentes educativos escolares y familiares resulta gravitante en el proceso educativo del alumnado. Siguiendo a Garreta y Maciá (2017) se identifican dos tipos de actividades o interacciones comunicativas: transmisión de información entre un emisor y un receptor (comunicación unidireccional) y, la repetición de ese esquema por parte del receptor (comunicación bidireccional).

Aunque en el contacto con las familias inmigrantes se suelen constatar las barreras lingüísticas de la comunicación, el análisis de los resultados evidencia la necesidad de ofrecer espacio de interacción con esas familias con el objetivo de compartir valores y expectativas educativas, puesto que el contacto con una nueva cultura educativa puede generar malentendidos. La evidencia investigativa demuestra la necesidad de velar por la comunicación afectiva con las familias si se pretende conseguir su implicación y colaboración con el sistema autóctono” (Vingut y Bertran, 2015, p. 48).

Garreta (2009) subraya que, en el caso de familias de origen migrado, en el aspecto comunicativo, re-sulta clave:

La comprensión del proyecto (migratorio y de vida) y, por tanto, de las expectativas educativas, actitudes (proyecto escolar para los hijos/as y capacidad de las familias para dirigirlo) así como la experiencia actual y previa con la escuela y sus profesionales. (p.16)

La generación de confianza entre familias y docentes depende de que exista buena voluntad, actitud y sentido de feedback en las relaciones de comunicación, que se pueden llevar por causas formales, pero también por causas informales, específicamente en las relaciones no institucionales (Andrés y Giró, 2016). Por lo tanto, la cercanía de los docentes con las familias es clave: "cultivarla es cultivar la participación, y generar climas de confianza, pero no existe mucha formación para ello y queda del lado de las habilidades personales y del grado de motivación de los docentes” (Andrés y Giró, 2016, p. 67). 


\subsection{Escuela y familias migrantes}

En el caso de las familias migrantes, el ingreso de los hijos al sistema escolar se convierte en un hito, porque ella cumple un rol en los procesos de integración social, al convertirse en un espacio de socialización y donde pueden construir relaciones y armar redes de apoyo (García-Yepes, 2017).

La evidencia investigativa indica, por un lado, que "los establecimientos sensibilizados con la temática migratoria se encuentran en un estado de integración más que de inclusión” (Joiko y Vásquez, 2016, p. 167); y por otro, que, como condición para avanzar en un sistema inclusivo e intercultural, potenciar la relación entre la escuela y la familia inmigrada pareciera ser un eje fundamental. El estudio de Joiko y Vásquez (2016), concluye que las instancias de encuentro entre ambas habitualmente:

Se dan espacios poco participativos y se traducen principalmente en reuniones de apoderados, dejar y/o buscar a los hijos y actos de in de año. Se sugiere, por ejemplo, una primera instancia de bienvenida para introducir a los padres en el sistema educativo, la cual a su vez podría incluir a toda la comunidad de padres, independiente de la nacionalidad. De esta manera, explicar el sistema de notas y evaluaciones, subvención escolar, entre otros temas relevantes para los padres. Aun cuando se reconoce que los establecimientos cuentan con manuales que explican esto, es importante también contar con espacios de participación que permitan a los padres poder preguntar y recibir respuestas a sus dudas. (p. 166)

En la línea de lo anterior, a pesar de que la estructura organizativa en los establecimientos educaciones públicos brinda espacios de participación como los Consejos Escolares, los estudiantes y familias migrantes lo hacen restringidamente (Cerón, Alvarado y Poblete, 2017). Entonces, resulta necesario potenciar el rol que tienen los establecimientos educacionales como:

Puentes entre las familias migrantes y su comunidad, ampliando el espacio de desarrollo de los estudiantes migrantes, evitando la conformación de trincheras familiares que conllevan a una doble marginación: externa, o nacida de las condiciones sociales, e interna, nacida de las propias familias migrantes que buscan protegerse mediante el aislamiento. (Bustos y Gairín, 2017, p. 215-216)

La marcada relación asimétrica entre escuela y familias nacionales, se replica también con las familias extranjeras, donde los docentes como agentes de la escuela, en su concepción de reproductora de un conocimiento monocultural, y por prejuicios culturales, desconoce que ellas también poseen "fondos de conocimientos" (Barquín, 2015), recursos educativos, que aportan a la formación y al éxito escolar de sus hijos/as. En esta línea, se destaca que el cuerpo docente valore dichos fondos de conocimiento que portan las familias minoritarias, "aquellos conocimientos culturalmente desarrollados e históri-camente acumulados y las destrezas esenciales para el funcionamiento y bienestar familiar o indivi-dual" (Barquín, 2015, p. 452).

La importancia de la relación escuela y familias migrantes radica en que ella favorece el proceso de inclusión educativa de los niños/as y jóvenes, mediado por "la efectividad de la relación de la familia con la vida del centro educativo y su participación en ella" (Colás, 2013, p. 208). Entonces, teniendo en cuenta estas consideraciones, emerge como objetivo principal del presente estudio, describir las visiones de los docentes sobre la participación de las familias migrantes en la escuela, en términos de cómo esta establece mecanismos de vinculación con los padres y cómo ellos participan en el proceso escolar de sus hijos/as. Como un objetivo complementario, también se realiza un acercamiento indagativo al consultar por las capacitaciones en educación de estudiantes migrantes o en educación intercultural que pudieron acceder los docentes que conforman el caso de estudio.

\section{Metodología}

El enfoque metodológico obedece al interés de esta investigación que responde a profundizar en las interpretaciones que los/as actores sociales manifiestan frente a un fenómeno, por lo tanto, se ha optado por una metodología cualitativa donde el/la investigador/a "privilegia lo profundo sobre lo superficial, lo intenso sobre lo extenso, lo particular sobre las generalidades, la captación del significado y del sentido interno, subjetivo, antes que la observación exterior de presuntas regularidades objetivas" 
(Vasilachis, 2006, p. 49). Para arribar a este propósito, la metodología cualitativa contempla el uso de "una variedad de materiales empíricos -estudio de caso, experiencia personal, introspectiva, historia de vida, entrevista, textos observacionales, históricos, interaccionales y visuales- que describen los momentos habituales y problemáticos y los significados en la vida de los individuos (Vasilachis, 2006, pp. 24-25).

En la presente investigación, se propone desarrollar un diseño investigativo de estudio de caso (Stake, 1998), método que resulta pertinente y natural para las investigaciones desde una perspectiva cualitativa (Sandín, 2003), la cual no requiere de un número excesivo de participantes, porque la metodología cualitativa no busca la cuantificación ni la generalización de los resultados, sino más bien, persigue estudiar de manera intensiva y profunda de un fenómeno (Hernández-Sampieri y Mendoza, 2018), a través del análisis de "casos concretos en su particularidad temporal y local, y a partir de las expresiones y actividades de las personas en sus contextos locales (Flick, 2012, p. 27).

El contexto del estudio fue un liceo público, Bicentenario ${ }^{1}$, mixto y actualmente es el establecimiento educacional que presenta mayor concentración de alumnado migrante en la región de Nuble (DAEM, 2019). Desde el año 2015 su matrícula revela un crecimiento de la presencia de alumnos extranjeros, a saber, 3 el año 2015; 6 en 2016; 4 en 2017, 24 en 2018 y en 2019 registra 40 alumnos/as extranjeros matriculados, en su mayoría provenientes de países latinoamericanos, correspondiendo al $4,5 \%$ del universo de 897 estudiantes adscritos al liceo.

Mediante un muestro no probabilístico de tipo intencional, basado en la "selección de sujetos particulares de la población que son representativos o informativos" (Cardona, 2002, p. 129), fue posible determinar como participantes del caso en estudio nueve docentes de enseñanza media, cuatro de la especialidad de Lenguaje y Comunicación y cinco, de Historia Geografía y Ciencias Sociales, resultando equitativa representación por género ( 4 mujeres y 5 varones), con un promedio de 20 años de experiencia docente. Los criterios de inclusión obedecen a que se desempeñen en uno de los establecimientos con mayor concentración de alumnado migrante de la comuna de Chillán ( $\tilde{N} u b l e$, Chile), cuenten con un mínimo tres años de experiencia docente con alumnado extranjero y accedan a participar en la investigación, expresando su voluntariedad mediante la firma de un consentimiento informado.

El acceso a los discursos de los participantes del estudio se realizó mediante la técnica de entrevista semiestructurada, que consideró las siguientes dimensiones: Participación de las familias migrantes en la escuela, Mecanismos de vinculación con los padres y Formación docente en Educación Intercultural. Ellas fueron abordadas a través de una entrevista que incluyó tres preguntas, a saber: a) ¿Cómo observa la participación de las familias migrantes en la escuela, en el proceso educativo de sus hijos?; b) ¿La escuela tiene algún tipo de protocolo de acogida, de inducción para las familias extranjeras? y c) ¿Usted como docente ha recibido alguna capacitación relacionada con educación de niños migrantes o educación intercultural?

Como técnica de análisis de los discursos declarados por los/as docentes se empleó el análisis cualitativo de contenido (Bardín, 1996), lo cual permitió el levantamiento de categorías de análisis, siguiendo un proceso inductivo, que Cáceres (2003) operacionaliza de la siguiente manera: Selección de un objeto de análisis; preanálisis, que incluye la recolección del corpus, formulación de guías e indicadores de temas; definición de las unidades de análisis, fragmentos seleccionados de acuerdo a criterios de inclusión/exclusión y que son codificados y posteriormente, categorizados; establecimiento de reglas de análisis y códigos de clasificación; desarrollo de categorías según criterios y por último, integración final de los hallazgos.

\section{Resultados}

Producto del análisis inductivo de los discursos de los/as docentes participantes en el caso de estudio, es posible levantar para cada dimensión, las siguientes categorías emergentes:

\footnotetext{
${ }^{1}$ Los Liceos Bicentenario "son un grupo de establecimientos que comparten tres principios de excelencia para entregar una educación de calidad: altas expectativas, foco en los aprendizajes y en la sala de clases"

(https://liceosbicentenario.mineduc.cl/que-es-un-liceo-bicentenario/)
} 
Cuadro 1

Categorías emergentes según dimensiones

\begin{tabular}{ll}
\hline \multicolumn{1}{c}{ Dimensiones } & \multicolumn{1}{c}{ Categorías emergentes } \\
\hline 1.Participación de las familias migrantes en el liceo & 1.1 Participación ajustada a la normativa del liceo 1.2 \\
& Participación condicionada por el trabajo \\
2.Mecanismos de vinculación con los padres migrantes & 2.1 Inducción estandarizada de lasamilias migrantes \\
3.Formación docente en Educación Intercultural & 3.1 Ausencia deormación en Educación Intercultural \\
\hline
\end{tabular}

Nota. Elaboración propia.

La dimensión Participación de las familias migrantes en la escuela, en primer lugar, revela que ella estaría ajustada a una Participación ajustada a la normativa del liceo.

Es así como, en los discursos docentes estaría predominando, en primer lugar, una visión positiva respecto de la participación de los padres, porque ella se presentaría alineada a lo normativo, donde los docentes valoran en los apoderados extranjeros su actitud de acatamiento de las normas del liceo:

Ellos justifican lasaltas a evaluaciones, que es una exigencia que se tiene aqui. Ellos vienen, no cuestionan. Esa es una cosa que yo he notado, ellos no dicen "¿pero por qué? ¿Y cómo? No. Le dices "usted tiene que venir cuando el alumno falte con justificado médico para que dé la prueba, para que tenga derecho a la nota real. Es lo que está en nuestro reglamento" y ellos dicen "perfecto, no hay problema". (Docente 3, Lenguaje)

En esta primera visión docente sobre la participación de las familias migrantes en la escuela chilena, el movimiento de la comunicación unidireccional (Escuela-familias) se interrumpe a partir de hechos conflictivos, casos donde son los padres migrantes quienes acuden al liceo. De acuerdo con las respuestas entregadas por los docentes, emergen como aspectos problemáticos dos situaciones, que son aludidas por varios profesores: una de tipo histórico y otra de tipo cultural. La situación conflictiva de tipo histórica refiere al conflicto marítimo entre Chile y Bolivia y la situación de tipo cultural, a la tradición de llevar el pelo largo por parte de un alumno perteneciente a una tribu de Ecuador. En el primer caso, los padres de una alumna boliviana reclamaron en el liceo por una broma referida al conflicto marítimo entre Chile y Bolivia, la cual fue espetada por un docente. Esta situación a juicio de una profesora hacía que los padres fuesen:

Muy sobreprotectores. Ellos tenían mucho terror y miedo a la temática del mar aquí en Chile, venían muy seguido al liceo y no dejaban a la niña desenvolverse tranquila en la escuela. Ellos venian arrancando del país debido al hostigamiento, etc. y habian tenido una mala experiencia en el norte. (Docente 1, Lenguaje)

En el segundo caso, los padres provenientes de Ecuador tomaron la iniciativa y se dirigieron al establecimiento, al parecer para prevenir un conflicto y así no contravenir el Reglamento de Convivencia del liceo, lo cual refuerza la idea de Participación ajustada a la normativa del liceo el cual no permite el pelo largo en los varones y el uso de vestimenta que no sea el uniforme del colegio. El alumno de Ecuador, explican dos docentes:

Viste a la usanza de pueblos ecuatorianos. Vestuario que es propio de su pueblo, se identifica con él, entonces los papás pidieron que no influyera el reglamento de convivencia, lo que son los reglamentos que hablan de vestuario y presentación personal porque ese vestuario le daba identidad al chico entonces no lo sacaban de sus raices. Entonces el liceo ha acatado esa situación. (Docente 8, Historia)

En segundo lugar, la primera dimensión de análisis es explicada desde la categoría emergente Participación condicionada por el trabajo, donde desde las visiones de los docentes adquieren una connotación negativa, ya que observan que no existiría una participación de las familias migrantes en la escuela. Coinciden en explicar esta situación atribuyendo a razones laborales de los padres, como lo señalan estas dos profesoras: 
No, no creo que haya una cosa, una participación, una presencia permanente de ellos, no. Porque ellos generalmente están trabajando. Entonces esa es su preocupación, ellos no tienen el tiempo o la disponibilidad para venirse a preocupar tanto de lo que es el colegio del alumno. Ellos están preocupados de trabajar, de forjarse un porvenir y los niños vienen a clases, estudian, vienen a las reuniones cuando tienen que venir. Pero, así como que, no sé, apoyen demasiado, no, no creo. (Docente 7, Historia)

Al consultar, ¿las familias vienen al establecimiento cuando las llaman o de mutuo propio?, el factor trabajo de los padres, vuelve a emerger como una barrera que se enfrenta a la organización rígida del liceo:

En general no [no vienen] porque están trabajando, a las reuniones, tarde maly nunca. Porque el horario de reuniones es 17:30 hrs. no es un horario tan flexible, y yo tengo horario de atención. Yo me comunico a través de ella (estudiante) “oye dile a tu madre...” (...) En reali-dad, no es que no quiera es que no puede, el horario de trabajo de ese tipo de trabajo no es muy grato y mi horario de atención no le acomoda, es imposible, si yo tengo horario de atención a las 10 de la mañana ¿Qué trabajador tiene posibilidad de salir a esa hora? Y si está recién llegado menos, imposible. (Docente 4, Lenguaje)

Se desprende además de estas respuestas, que a pesar que el profesorado declara conocimiento de la situación que viven dichos apoderados debido a su condición de trabajadores migrantes, aquello no permea las formas de gestionar el vínculo con los padres, resultando entonces incompatibles las formas escolares con la realidad que experimentan estas familias que emigraron en busca de mejores expectativas laborales:

Entonces ¿Cuándo van los padres a la escuela? o ¿Cómo se vinculan los padres migrantes con la escuela? Lo estarian haciendo conminados por el reglamento y de manera reactiva por algún problema que vivan sus hijos/as en el liceo; estableciéndose una relación escuelocéntrica, que ejerce un accionar homogeneizador frente a las familias migrantes, acudiendo estas al liceo “cuando las llaman”. (Docente 9, Historia)

En cuanto a la segunda dimensión referida a Mecanismos de vinculación con los padres migrantes es posible explicarla a través de la categoría emergente Inducción estandarizada de las familias migrantes, donde las respuestas de los docentes en su totalidad revelan que el liceo no cuenta con protocolos de acogida para las familias de estudiantes migrantes, pero que el establecimiento realiza acciones de inducción a los apoderados que ingresan cada año al liceo, indistintamente sea su nacionalidad. Es decir, los apoderados extranjeros resultan invisibilizados, son considerados en la categoría de "apoderados nuevos" al igual que sus pares nacionales:

No, lo que se hace acá en el liceo es una inducción para todos. Siempre a principio de año se hace, bueno el primer día hay una bienvenida y obviamente los apoderados que son nuevos llegan con sus hijos. Los vienen a dejar, se le hace un saludo a la bandera (...). Por lo general se hace el día de reunión de apoderado, se invita primero al salón y luego cada uno va a su sala. (Docente 3, Lenguaje)

Esta docente, también destaca el momento cuando los padres matriculan a su hijo/a en el liceo, como parte de la inducción, porque allí se le entrega documentación:

$Y$ además cuando se viene a matricular a los alumnos se les entrega todo el material sobre todo lo que deben saber de la reglamentación interna del establecimiento. Se les entrega copia del PEI, del reglamento de evaluación y el reglamento de convivencia. (Docente 3 , Lenguaje)

A su vez, la invisibilización que desemboca en el trato homogéneo que la escuela da a los padres se extiende a sus hijos/as, porque el profesorado no recibe información desde los directivos de la llegada de un estudiante extranjero:

Pero más allá de que nosotros se nos presente a la alumna como por UTP una reunión específica, nada. Uno tiene que adivinar poco menos cuando llega a la clase y encuentra un acento extraño ahí conversa con el alumno para saber qué pasa. (Docente 1, Lenguaje). 
A lo anterior se suma el desconocimiento por parte de los docentes de la existencia o no de un protocolo de acogida para el estudiante de extranjero y su familia "No, esa parte no sé. Pero a los alumnos si los integran rapidito" (Docente 5, Historia); integración que deviene más bien en asimilación,

Tal vez no se hace una inducción individualizada para la gente de afuera, se toma a todo el grupo general y se les da a todos el mismo contenido. (Docente 9, Historia)

Esta invisibilización-homogenización de las familias y alumnado migrante, cuya presencia no es informada desde los directivos del establecimiento al profesorado, podría ser un factor que coayuda a los escasos espacios de relación entre los actores y que profundizaría la distancia entre ellos, emergiendo así mecanismos suplentes a quienes se responsabilizaría de labor de integración, como los equipos multidisciplinarios del establecimiento. "Ellos hacen ese trabajo", declara el Docente 2, Lenguaje, evidenciando un ejercicio de desresponsabilización por parte del docente en cuanto a su rol coayudante en la integración de las familias de estudiantes migrantes en la escuela.

Y, por último, la dimensión Formación docente en Educación Intercultural, resulta explicada mediante la categoría emergente Ausencia de formación en Educación Intercultural, la cual revela que los docentes de este caso de estudio, en su totalidad declara no haber recibido ningún tipo de formación en dichas materias, tanto en su etapa de estudiante de pedagogía como en el ejercicio profesional, a pesar que hubo una intención en alianza con una universidad local: "Este año quedaron de darnos la capacitación pero no pasa nada" (Docente 5, Historia), Algunas voces del profesorado explican este hecho argumentando que la llegada de estudiantes extranjeros es reciente (Docente 3, Lenguaje) y a la ausencia de barreras idiomáticas, pero:

Cuando llegue un extranjero con que nadie sepa comunicarse con él, probablemente lo vean como una necesidad. Yo creo que aún no lo han hecho porque recién se está viendo, así como el duro de la inmigración. (Docente 3, Lenguaje)

Es decir, los vacíos formativos frente a esta realidad nueva en la escuela se suplen de manera reactiva a través de dos mecanismos, el primero de ellos la improvisación:

Bueno, toda la vida ha existido migrantes, pero el boom de chiquillos tan chicos migrantes, no. Entonces no hay una experiencia, no hay un protocolo a seguir, introducir, inducir, explicarles. Se ha ido como arreglando en el camino no más, de hecho, en el camino se arregló que las chiquillas tenian que bajar de curso. Las chiquillas que estaban en Cuarto, las melli-zas que estaban en Cuarto se bajaron a Segundo. (Docente 4, Lenguaje)

Y el segundo mecanismo, referido a la intuición, como lo declara la siguiente voz docente:

Hemos conversado sí en consejo. Pero capacitación de alguien, sociólogo, psicólogo, al menos yo no me consta. Así que todo se hace aqui por intuición y cuando se presenta alguna situación especial se conversa en consejo. (Docente 8 , Historia)

En resumen, a partir del estudio desarrollado emergieron visiones docentes contrapuestas sobre la participación de las familias migrantes en la escuela chilena. Por una parte, una visión positiva que estima que sí existe participación, la cual responde a las normas del colegio donde los docentes valoran en los apoderados extranjeros su actitud más bien de sumisión a las normas del establecimiento; y por otra parte, emerge una visión negativa, que aludiría a la ausencia de participación de los padres extranjeros, quienes, a juicio de los docentes, se ven coartados por sus compromisos laborales a tener una mayor participación en el proceso escolar de sus hijos/as.

\section{Discusión y conclusiones}

De acuerdo al objetivo principal del estudio, describir las visiones de los docentes sobre la participación de las familias migrantes en la escuela, en términos de cómo esta establece mecanismos de vinculación con los padres y cómo ellos participan en el proceso escolar de sus hijos/as, se puede concluir que las visiones docentes contrapuestas acerca de la participación de las familias migrantes en la escuela, dan cuenta de un concepto de participación ajustado a la norma escolar, derivado del establecimiento de una relación escuelocéntrica. 
Desde la visión positiva, el profesorado de este caso de estudio valora la presencia de este grupo familiar, porque ellos al acatar la normativa del establecimiento resultarían ser una especie de "apoderado ideal", en contraste con los apoderados nacionales. No obstante, en dicho concepto de participación de las familias migrantes, subyace un modelo tradicional en la visión de los docentes, donde el rol de los padres aparece subyugado a las directrices de la escuela, y donde también los canales de comunicación son unidireccionales; es decir, impuestos por el establecimiento y los usuales, siendo la reunión de padres y la entrevista casi los únicos mecanismos de vinculación. Además, el análisis de los discursos del profesorado en estudio pone en evidencia la ausencia de protocolos de acogida específicos para este grupo de familias.

A su vez, y desde la visión negativa que manifiestan los docentes en este estudio, los argumentos que entregan los docentes para explicar la no participación de los padres migrantes, responde a un "querer-no poder", parafraseando las categorizaciones de juicios del profesorado sobre las familias que se alejan de la norma escolar planteadas por Río (2010). Uno de los rasgos destacados en las familias inmigradas es la valoración que realizan de la educación como vía de acceso a una mejor condición de vida; no obstante, su participación en la escuela se limita por las condicionantes laborales, generalmente precarias que les aquejan en el país de acogida.

Entonces, la escuela subraya su rigidez y falta de empatía frente a las condiciones laborales y económicas que enfrentan las familias migradas, siendo esta una de las vulnerabilidades de los estudiantes migrantes en el sistema escolar en Chile, asociadas a factores estructurales (Stefoni et al., 2010). Resulta ser una vulnerabilidad, porque "las condiciones laborales inciden negativamente en la forma y posibilidades que tienen los padres de los niños/as migrantes de atender y acompañar el proceso de inserción en sus escuelas” (p. 64).

Este ajuste a la norma escolar podría estar siendo interpretado por los docentes como un indicador de integración de las familias migradas al sistema escolar nacional, quedando así en un segundo plano la cuestión de fondo: el descarte de los saberes culturales que portan las familias migrantes, no observándose en los discursos de los docentes un interés por ello ni por ahondar en sus experiencias en su rol de apoderados en sus países de origen. No se evidencia en este estudio de caso, alusiones a repensar la actividad escolar ni la relación Escuela-familias, en torno a las culturas familiares, en el sentido de generar mecanismos de participación en la vida del liceo, ya sea en colaboración dentro del aula o siendo partícipe en actividades del establecimiento (Barquín, 2015).

En cuanto a la elección de establecimiento educacional por parte de las familias migrantes, no existe aún suficiente evidencia investigativa "a pesar de ser un proceso más complejo, ya que tienen que tomar una decisión sobre la base de sus expectativas y percepciones, en un escenario que muchas veces no pueden comprender a cabalidad" (Joiko y Vásquez, 2016, p. 142). En el caso de las familias migrantes de sectores bajos y medio-bajos se constatan "mayores restricciones para elegir un colegio. En la medida de lo posible se buscan colegios con un buen desempeño académico y que proteja a los menores de la discriminación." (Stefoni et al., 2010, p. 71).

En relación al objetivo complementario de esta investigación, en vista de la ausencia de formación en educación de estudiantes migrantes o en Educación intercultural, los resultados del estudio corroboran lo planteado por Beech y Princz (2012), que la educación del alumnado migrante queda al arbitrio y la ideología de los docentes, y no responde a una organización ni política educativa determinada. No obstante, al parecer existiría conciencia por parte del profesorado chileno de esta debilidad en su formación, según reporta la Encuesta Internacional de Enseñanza y Aprendizaje TALIS 2013, desarrollada por la OECD y aplicada a los profesores y directores de escuela. Los resultados consignan que unas de las áreas con mayor necesidad de desarrollo profesional para el profesorado chileno son "enseñanza a estudiantes con necesidades especiales" y "enseñanza en entornos multiculturales o multilingües", ambas muy por encima del promedio TALIS (25,8\% y 24,4\% v/s 22,3\% y 12,7\% respectivamente" (Mineduc, 2014).

Por su parte, la necesidad de formación de profesorado en educación multicultural y educación antirracista forma parte de las conclusiones a las cuales arriban investigaciones desarrolladas tanto en el contexto educacional chileno como extranjero (Aranda, 2017; Jiménez, 2014; Jiménez y Montecinos, 2018; Jiménez, Lalueza y Fardella, 2017; Riedemann y Stefoni, 2015; Sánchez, Navas y Holgado, 2013; Sanhueza, Friz y Quintriqueo, 2014). 
Indagar en las visiones de los docentes resulta de relevancia para conocer sus opiniones y reporta información ya sea para poner en tensión la Formación Inicial Docente o para el diseño de programas de formación continua que aborden tanto la temática de la relación escuela y familias en general, como la relación escuela y familias migrantes, en particular. Lo anterior en vista de cómo las comunidades educativas podrían mejorar esa relación con el propósito de entregar una educación de calidad integral, tarea que el sistema educacional chileno debe asumir con urgencia de cara a los nuevos desafíos que imponen las aulas culturalmente diversas.

Frente a la rigidez de la escuela frente a la situación de las familias migrantes, la respuesta estaría en el fomento de una educación flexible, capaz de "dar respuesta, a través de distintos métodos, a las necesidades y características de los estudiantes y de los diversos contextos sociales y culturales. En otras palabras, la recomendación sería transitar desde una pedagogía de la homogeneidad hacia una pedagogía de la diversidad, como una oportunidad para enriquecer los procesos de enseñanza y aprendizaje, y optimizar el desarrollo personal y social” (Gubbins, 2016. p. 32).

Como limitaciones del estudio es posible destacar que no se consideraron como participantes de la investigación a los padres y madres de los estudiantes migrantes matriculados en el establecimiento escolar al cual están adscritos los docentes que conformaron el caso estudiado. Esto, sin duda, abre una línea de investigación necesaria de abordar a mediano plano, lo cual permitiría obtener una mirada integral del fenómeno, así como también emerge como un futuro estudio la indagación de buenas prácticas de participación de familias migrantes en el proceso de aprendizaje de sus hijos/as.

\section{Agradecimientos}

Este trabajo fue posible gracias a la Beca CONICYT PFCHA/DOCTORADO NACIONAL/2017 (folio 21170381) y desarrollado mientras cursaba el programa de Doctorado en Educación en Consorcio. Universidad del Bío-Bío, Chile.

\section{Referencias}

Andrés, S. y Giró, J. (2016). El papel y la representación del profesorado en la participación de las familias en la escuela. Revista Electrónica Interuniversitaria de Formación del Profesorado, 19(1), 61-71.

Aranda, V. (2017). Educación intercultural para la formación inicial docente: Una investigación acción con estudiantes de pedagogía. En F. Lillo (Ed.), Migración y educación: interpelación a las sociedades plurales (pp. 97-123). Ediciones Universidad Católica del Maule.

Bardín, L. (1996). El análisis de contenido. Akal.

Barquín, A. (2015). ¿Qué debe hacer la escuela con las culturas familiares del alumnado inmigrante? Educar, 51(2). 443-464. https://doi.org/10.5565/rev/educar.671

Beech, J. y Princz, P. (2012). Migraciones y educación en la ciudad de Buenos Aires: Tensiones políticas, pedagógicas y étnicas. Revista Latinoamericana de Inclusión Educativa, 6(1), 53-71.

Beniscelli, L., Riedemann, A. y Stang, F. (2019). Multicultural, y sin embargo asimilacionista. Paradojas provocadas por el currículo oculto en una escuela con alto porcentaje de alumnos migrantes. Revista Calidad en la Educación, 50, 393-423. https://doi.org/10.31619/caledu.n50.522.

Bustos, R y Gairín, J. (2017). Adaptación académica de estudiantes migrantes en contextos de frontera. Revista Calidad en la Educación, 46, 193-220. https://doi.org/10.4067/S0718-45652017000100193

Cáceres, P. (2003). Análisis cualitativo de contenido: Una alternativa metodológica alcanzable. Psicoperspectivas, $2(1), 53-82$.

Cardona, M. (2002). Introducción a los métodos de investigación en educación. EOS. 
Cerón,L.,Pérez,M.yPoblete,R.(2017).Percepcionesdocentesentornoalapresenciadeniñosyniñasmigrantesenescuelas de Santiago: Retos y desafíos para la inclusión. Revista Latinoamericana de Educación Inclusiva, 11(2), 233-246. https://doi.org/10.4067/S0718-73782017000200015

Cisternas, N., Jara, L. y Vuollo, E. (2019). Luces y sombras de la inclusión de estudiantes migrantes en Chile. En N. Rojas y J. Vicuña (Eds.), Migración en Chile. Evidencia y mitos de una nueva realidad (pp. 73-106). LOM.

Colás, P. y Contreras, J. (2013). La participación de las familias en los centros de educación primaria. Revista de Investigación Educativa, 31(2), 485-499. https://doi.org/10.6018/rie.31.2.171031

DAEM. (2019). Matrícula de alumnos/as migrantes por establecimiento en los últimos cinco años. Chillán.

Flick, U. (2012). Introducción la investigación cualitativa. Morata.

García-Yepes, K. (2017). (2017). Procesos de integración social de inmigrantes en escuelas de Huelva, España. Alteridad, 12(2), 188-200. https://doi.org/10.17163/alt.v12n2.2017.05

Garreta, J. (2009). Escuela y familias inmigradas: Relaciones complejas. Revista Complutense de Educación, 20(2), $1-18$.

Garreta, J. y Maciá, M. (2017). La comunicación familia-escuela. En J. Garreta (Coord.), Familiasy escuelas. Discurso y prácticas sobre la participación en la escuela (pp. 71-98). Ediciones Pirámide.

Giró, J. y Andrés, S. (2017). La participación del profesorado en la escuela. En J. Garreta (Coord.), Familias y escuelas. Discurso y prácticas sobre la participación en la escuela. (pp. 125-147). Ediciones Pirámide.

Gubbins, V. (2016). Relación familiasy escuelas: ¿por quéy para qué? En V. Gubbins (Ed.), Educación de calidad: El desafío de la comunidad escolar (pp. 19-50). Ediciones Universidad Finis Terrae.

Hernández-Sampieri, R. y Mendoza, C. (2018). Metodología de la investigación. Las rutas cuantitativa, cualitativa y mixta. McGraw-Hill.

INE. (2018). Síntesis de resultados Censo 2017. Instituto Nacional de Estadísticas Chile.

Jiménez, F. (2014). Modelos de gestión de la diversidad cultural para la escolarización de alumnado inmigrante en las escuelas chilenas: Desafíos para la interculturalidad actual. Estudios Pedagógicos, 40(2), 409-426. https://doi.org/10.4067/S0718-07052014000300024

Jiménez, F. y Montecinos, C. (2018). Diversidad, modelos de gestión y formación inicial docente: Desafíos formativos desde una perspectiva de justicia social. Revista Brasileira de Educação, 23, 1-21. https://doi.org/10.1590/s1413-24782018230005

Jiménez, F., Lalueza,J. L.y Fardella, K. (2017). Aprendizajes, inclusión y justicia social en entornos educativos multiculturales. Revista Electrónica de Investigación Educativa, 19(3), 10-23. https://doi.org/10.24320/redie.2017.19.3.830

Joiko, S. y Vásquez, A. (2016). Acceso y elección escolar de familias migrantes en Chile: No tuve problemas porque la escuela es abierta, porque acepta muchas nacionalidades. Calidad en la Educación, 45, 132-173. https://doi.org/10.4067/S0718-45652016000200005

Layton, K. (2013). Más allá de las fronteras: pasos hacia la educación intercultural basados en la experiencia con alumnos migrantes en 6 escuelas primarias en Buenos Aires, Argentina y Santiago, Chile. Independent Study Project (ISP) Collection.

Mineduc. (2014). Encuesta internacional de enseñanza y aprendizaje. Mineduc.

Mineduc. (2016). Orientaciones para la construcción de comunidades educativas inclusivas. Mineduc.

Mineduc. (2018a). Mapa del estudiantado extranjero en el sistema escolar chileno (2015-2017). Mineduc.

Mineduc. (2018b). Política nacional de estudiantes extranjeros. 2018-2022. Mineduc.

Mora-Olate, M. L. (2018). Política educativa para migrantes en Chile: Un silencio elocuente. Polis, Revista Latinoamericana, 49, 231-257. https://doi.org/10.4067/S0718-65682018000100231

Mora-Olate, M. L. (2020). Currículum y diversidad cultural: Un estudio desde disciplinas escolares y discursos docentes en establecimientos educacionales con alumnado de origen migrante (Tesis doctoral). Universidad del Bío-Bío, Chile. 
Nakamura, P. (2011). La inclusión de las familias inmigrantes en la escuela: El caso de una comunidad peruana en Japón. REICE. Revista Iberoamericana sobre Calidad, Eficacia y Cambio en Educación, 9(4), 159-173.

Riedemann, A. y Stefoni, C. (2015). Sobre el racismo, su negación, y las consecuencias para una educación anti-racista en la enseñanza secundaria chilena. Polis, Revista Latinoamericana, 14(42), 191-216. https://doi.org/10.4067/S0718-65682015000300010

Río, M. (2010). No quieren, no saben, no pueden: Categorizaciones sobre las familias más alejadas de la norma escolar. Revista Española de Sociología, 14, 85-105.

Sabariego, M., Massot, I. y Dorio, I. (2012). Métodos de investigación cualitativa. En A. Bisquerra (Coord.), Metodología de la investigación educativa (pp. 293-328). La Muralla.

Sánchez, A., Navas, L. y Holgado, P. (2013). Inmigración y educación intercultural en la formación inicial docente. Estudios Pedagógicos, 39(1), 239-251. https://doi.org/10.4067/S0718-07052013000100014

Sandín, M. P. (2003). Investigación cualitativa en educación: fundamentos y tradiciones. Mc Graw Hill.

Sanhueza, S., Friz, M. y Quintriqueo, S. (2014). Estudio exploratorio sobre las actitudes y comportamiento del profesorado de Chile en contextos de escolarización de alumnado inmigrante. Revista Electrónica de Investigación Educativa, 16(3), 148-162.

Stefoni, C., Acosta, E., Gaymer, M. y Casas-Cordero, F. (2010). El derecho a la educación de los niñosy niñas inmigrantes en Chile. Universidad de Deusto.

Vasilachis de Gialdino, I. (2006). Estrategias de investigación cualitativa. Gedisa.

Vigo, B., Dieste, B. y Julve, C. (2017). Discursos sobre participación de las familias en la escuela y éxito escolar. En J. Garreta (Coord.), Familias y escuelas. Discurso y prácticas sobre la participación en la escuela (pp. 149-162). Biblioteca Universitaria.

Vingut, M. y Bertran, M. (2015). Educación infantil y familias inmigrantes: Posibilidades y limitaciones comunicativas. Revista Italiana di Educazione Familiare, 1, 33-51.

Viveros, L. y Cárcamo, H. (2019). Etnografiando la relación familia-escuela. El caso de una escuela municipal de la ciudad de Chillán, Chile. Revista Reflexión e Investigación Educacional, 2(1), 57-82.

\section{Breve CV de la autora}

\section{María Loreto Mora-Olate}

Doctora en Educación, Magíster en Educación y Profesora de Castellano y Comunicación Social (Universidad del Bío-Bío, Chile). Máster en Educación, Asesoramiento Educativo Familiar (Centro Universitario Villanueva, Universidad Complutense de Madrid, España - Santiago de Chile). Becaria CONICYT (2017-2020). Investigadora del Grupo de investigación "Literatura y Escuela” (LyE) en la Universidad Autónoma de Chile (Chile), Grupo de Investigación "Familia, Escuela y Sociedad" (FESOC) en la Universidad del Bío-Bío y Grupo de Investigación en "Migración e Interculturalidad"(GRIMI) en la Universidad Católica del Maule (Chile). Es autora de varios artículos sobre migración en contexto escolar. Email: maria.mora@uautonoma.cl

ORCID ID: https://orcid.org/0000-0002-7631-9179 